\title{
Kidney Cancer pT4 TNM Finding v8
}

National Cancer Institute

\section{Source}

National Cancer Institute. Kidney Cancer pT 4 TNM Finding v8. NCI Thesaurus. Code C140295.

Kidney cancer in which the tumor invades beyond Gerota's fascia (including contiguous extension into the ipsilateral adrenal gland). (from AJCC 8th Ed.) 